\title{
MOBILIDADE COMO FOCO DAS TECNOLOGIAS DE VIGILÂNCIA*
}

\section{Marta Mourão Kanashiro}

\section{Introdução}

As tecnologias de vigilância e monitoramento para a segurança, cada vez mais recorrentes nas sociedades contemporâneas ocidentais, conectamse a importantes transformações sociais e a diferentes temas pesquisados nas ciências sociais. $\mathrm{O}$ foco sobre a presença dessas tecnologias em espaços de circulação pública abre diversas possibilidades analíticas, seja por sua proximidade com o campo da

* Agradeço os interessantes comentários e sugestões dos pareceristas, assim como o incentivo dos professores Rodrigo Firmino e Rossana Rocha Reis. O atual texto recebeu modificações sugeridas pelos pareceristas, sendo que uma primeira versão foi publicada nos Anais do XXXI Encontro Anual da Anpocs, em virtude de sua apresentação no Seminário Temático "Imigração como perigo: antigas questões, novos desafios".

Artigo recebido em marco/2008

Aprovado em abril/2009 sociologia da tecnologia, seja pela interface que pode ser estabelecida com áreas como a de urbanismo e arquitetura, geografia ou temas como violência, criminalidade e segurança. Em todos esses casos é importante ressaltar que o olhar que parte da tecnologia não deve pressupor que exista uma determinação da técnica sobre as transformações que se queira observar ou salientar.

Nesse sentido, o presente artigo ressalta a participação das tecnologias de monitoramento nas transformações sociais, políticas, econômicas e culturais na contemporaneidade. Distante de avaliar a necessidade ou a validade dessas tecnologias para segurança, a escolha por esse ponto de partida deve-se ao ângulo de visão que essas tecnologias proporcionam. A tecnologia formulada pelo homem incorpora, abriga, concretiza e concentra um modo de pensamento e pode ser um ângulo privilegiado para fazer emergir as visibilidades e invisibilidades de uma época, 
ou, ainda, funcionar heuristicamente como ponto de partida para uma investigação acerca dos dispositivos de funcionamento do poder na atualidade.

De forma geral, esse é um campo relativamente recente de debates e pesquisas. A maior parte das iniciativas sobre o tema voltadas para estudos da vigilância são britânicas, canadenses e norte-americanas. Destaca-se aqui o empreendimento de pesquisadores do Reino Unido para reunir estudiosos na Surveillance Studies Network (http://www. surveillance-studies.net), no periódico Surveillance \& Society (http://www.surveillance-and-society.org/ info.htm ) e no projeto canadense de pesquisa Surveillance Project. Já no âmbito dos movimentos sociais e das organizações não governamentais (Ongs), ressaltam-se: a Privacy International Organization (www.privacyinternational.org), uma organização, situada em Londres desde 1990, para monitorar formas de vigilância e de invasão da privacidade realizadas por governos e corporações, e a Electronic Frontier Foundation (http://www.eff. org/), que tem uma forma de atuação semelhante e está situada nos Estados Unidos, também desde 1990. Paralelamente, performances artísticas têm questionado e problematizado a presença das tecnologias de monitoramento no cotidiano, como é o caso do Surveillance Camera Players, grupo de Nova York que realiza desde 1996 intervenções em espaços públicos monitorados.

Diferentemente do que vem ocorrendo no ambiente acadêmico internacional, pesquisas brasileiras que versem de modo direto sobre a utilização de tecnologias eletrônicas que possibilitam a vigilância e o monitoramento ainda são bastante incipientes. Da mesma forma, é praticamente inexistente o debate político ou a atuação de movimentos sociais no país em torno desse tema, ou de assuntos como vigilância eletrônica. ${ }^{1}$ Por outro lado, a exemplo do que ocorre em várias partes do mundo, multiplicam-se no país os projetos de utilização dessas tecnologias de monitoramento, em especial para segurança em espaços de circulação pública e, mais recentemente, projetos para utilização de dispositivos biométricos de controle e para a incorporação da biometria em documentos.

Como parte do projeto de pesquisa "Dispositivos biométricos no Brasil: a expansão das novas tecnologias de segurança" (Kanashiro, 2007), que tem como um de seus focos a biometria no passaporte brasileiro, este artigo traz um levantamento de algumas abordagens que conectam mobilidade, tecnologias de vigilância e circulação internacional de pessoas com novas representações e definições de perigo e insegurança. O levantamento foi realizado sobretudo em artigos internacionais que tematizam a questão. Para a análise desses artigos são retomados conceitos e problematizações presentes em autores como Paul Virilio, Michel Foucault e Gilles Deleuze.

Este texto traz inicialmente parte do levantamento de dados (realizado em 2007) sobre a inclusão da biometria no passaporte brasileiro, em conexão com reflexões presentes em uma pesquisa realizada entre os anos de 2002 e 2005 (Kanashiro, 2006 e 2008). Nessa ocasião, observou-se a relação das câmeras de vigilância com o tema de revitalização urbana, antigos centros das cidades que vêm sofrendo intervenções no sentido de tornarem-se locais de lazer, cultura e fruição mais seguros para determinados grupos, aprofundando mecanismos de exclusão. Concluiu-se que mais do que sobre cada indivíduo, ou para além da abordagem foucaultiana sobre panóptico, a vigilância realiza-se focalizando a mobilidade e os fluxos de pessoas e informações. Notou-se, nesse contexto, um investimento de um grupo social sobre a expansão de sua própria mobilidade. Em outras palavras, um processo de restrição da mobilidade de alguns grupos sociais, a qual passa a ser ainda mais circunscrita às áreas precárias da cidade, em prol da ampliação do movimento de outros grupos sociais normalmente relacionados com os enclaves fortificados. Assim, a segunda parte deste artigo salienta que a configuração da inserção da biometria no passaporte também está relacionada com o controle da mobilidade, dos fluxos, e com novos significados de perigo e risco, como vem sendo apontado na bibliografia internacional.

A intenção aqui é vislumbrar tecnologias, como as câmeras de monitoramento ou a biometria incorporada aos passaportes, não mais vinculadas ao lugar ou tempo adequados para a punição exemplar da sociedade disciplinar foucaultiana, mas sim à permissão ou à recusa do acesso, o que desloca e dilui 
a punição para o momento sempre imediato da mobilidade, da circulação. Associam-se a essa idéia as características das sociedades contemporâneas e os conceitos apresentados por Virilio e Deleuze.

Diversamente da aproximação feita sobre o tema nas cidades, que relacionam as câmeras com o processo de revitalização ou o fenômeno de gentrificação, estudos internacionais sobre vigilância focalizam mais as questões relativas à migração e à representação de perigo vinculada ao tema. Alguns autores (Lyon, 2006) têm observado um recrudescimento da questão securitária e do foco sobre mobilidades e circulação a partir do ataque terrorista ao World Trade Center, nos Estados Unidos, em 2001.

\section{A biometria no passaporte brasileiro}

A biometria é definida como um estudo das medidas de estruturas e órgãos de seres vivos, associadas à sua importância funcional. Há também um ramo da estatística vinculado à ecologia, no qual se estudam as características biológicas quantitativas de uma população por meio da identificação dessas medidas. Mais recentemente, no entanto, a biometria tem sido definida pela mídia e pelo mercado de segurança como "uma ciência de identificação baseada na medição precisa de traços biológicos". ${ }^{2}$ Em outras palavras, quando entendida como tecnologia de segurança, a biometria é caracterizada pela coleta de dados biológicos, que podem ser da íris, da retina, da face, da mão ou de digitais, entre outras possibilidades, e transforma-os em algoritmos matemáticos, armazenando-os em bancos de dados, chips ou códigos de barra. Por meio de um leitor óptico, as características biológicas são lidas e comparadas com os dados armazenados para identificar, negar ou permitir o acesso a determinados lugares ou informações.

De acordo com a revista Security:

[...] biometria significa literalmente medida da vida. No contexto da segurança, biometria se refere aos métodos automatizados para identificação de pessoas com base em suas características físicas únicas ou aspectos comportamentais, podendo ainda combinar entre si essas características. A biometria funciona em razão de algumas características do ser humano serem únicas, podendo ser diferenciadas e comparadas, pois de certa forma, são estáveis. ${ }^{3}$

A mídia e os empresários do setor de segurança vêm divulgando a nova tecnologia como uma substituição das senhas alfanuméricas pela identificação via "senha natural", ou seja, por meio dos dados biológicos inscritos no próprio corpo. A mudança também é apresentada como uma facilidade oferecida pela tecnologia para possibilitar o controle do acesso, como uma comodidade, na medida em que evita a memorização ${ }^{4}$ de tantas senhas, e como um incremento do nível de segurança dos sistemas. Esse panorama acaba por promover um verdadeiro investimento sobre características biológicas que identifiquem pessoas.

Essa tecnologia já está presente no Brasil para o controle de acesso a lugares como academias de ginástica, universidades ou escolas privadas e para o controle da utilização de serviços, como locação de filmes em vídeo locadoras ou consultas e exames em sistemas privados de saúde, caso da Unimed Paulistana. Pode ainda ser utilizada nos sistemas carcerário, de saúde e bancário para controle de ponto de trabalhadores e muitos outros usos. A tecnologia biométrica de identificação no setor de segurança já é encontrada na prática e está em rápida expansão em vários países, configurando um fenômeno complexo das sociedades contemporâneas.

No Brasil, existem também exemplos da utilização dessa tecnologia em serviços públicos, entre outros casos, a implantação do Sistema de Gerenciamento de Formação de Condutores (Gefor), do Departamento Estadual de Trânsito (Detran) de São Paulo, destinado ao gerenciamento, ao controle e à fiscalização de todo o processo de habilitação, formação e reciclagem de condutores. Esse sistema implantou a biometria, via leitura da impressão digital, para todos esses procedimentos em várias cidades do estado. ${ }^{5}$ Outros projetos de adoção da tecnologia biométrica no Brasil são do Tribunal Superior Eleitoral (TSE), que aprovou em junho de 2005 o "Plano diretor de atualização cadastral e aperfeiçoamento dos sistemas de votação e identificação do 
eleitor", e do Ministério da Justiça que, em conjunto com outros órgãos do governo, tem se dedicado a implementar o Projeto de Registro de Identidade Civil (RIC). Com relação ao projeto do TSE, que prevê o recadastramento de 122 milhões de eleitores no país, já foi iniciada uma fase de testes no segundo semestre de 2008, durante as eleições municipais em Fátima do Sul, no Mato Grosso do Sul, São João Batista, em Santa Catarina, e Colorado d'Oeste, em Rondônia, todos com cerca de 15 mil habitantes cada. Nesses locais foi realizado o cadastramento biométrico dos eleitores e a votação com uso de urna biométrica nas eleições municipais de outubro. A partir desse projeto piloto o governo deverá elaborar o cronograma para o recadastramento nacional de eleitores, num prazo estimado entre 5 e 10 anos. Já o projeto RIC visa à modificação das carteiras de identidade de 150 milhões de cidadãos brasileiros, prevista na lei ainda 9.454 de 1997, que ainda não está regulamentada. A ausência de regulamentação, no entanto, não tem sido um empecilho para a implementação e o teste do novo sistema de identificação civil, que já está sendo iniciada na capital de Rondônia. ${ }^{6}$

O projeto do novo passaporte brasileiro, aqui focalizado, é uma outra iniciativa que prevê a utilização da biometria. Entre vinte itens de segurança, o novo passaporte inclui dados biométricos do portador, os quais farão parte de um banco de dados nacional e, de acordo com o projeto, facilitarão as consultas em postos de fronteira. Um informativo da Polícia Federal brasileira divulgou que a inclusão da biometria segue as exigências de mudança e as normas internacionais de segurança estabelecidas pela Organização de Aviação Civil Internacional (Icao, sigla em inglês), agência ligada às Nações Unidas, responsável por normatizar assuntos relativos à aviação civil e aos vistos e documentos de viagem. ${ }^{7}$ De acordo com esse informativo, a adequação irá, "efetivamente, implementar um documento de viagem mais seguro, que propicie ao cidadão brasileiro maior credibilidade internacional, além de modernizar todo o sistema de controle do tráfego internacional no país". ${ }^{8}$

O novo passaporte brasileiro é assim apresentado pelo governo: "Segurança, agilidade e conforto. Seguro e moderno, o novo passaporte brasileiro proporciona agilidade, praticidade e conforto aos cidadãos brasileiros. A tecnologia de ponta utilizada neste projeto oferece excelente proteção contra tentativas de adulteração e/ou falsificação". ' Os novos itens de segurança apresentados, que se somam aos anteriormente existentes, são marca d'água, fio de segurança, linha de costura, fundo invisível, fundos especiais, imagem latente, tinta oticamente variável, perfuração a laser, página de identificação e laminado de segurança. É na página de identificação que há um código de barras bidimensional, ${ }^{10}$ com dados biométricos e biográficos do titular do documento. Ela segue as recomendações da Icao (International Civil Aviation Organization), em especial as do DOC 9303. Este documento, publicado pela primeira vez em 1980, intitulado como "A passport with machine readable capability" está hoje publicado em três partes. Cada uma delas traz recomendações técnicas para utilização da biometria nos passaportes.

Além de seguir as recomendações da Icao, as medidas para a implementação de um novo passaporte brasileiro também ecoam a iniciativa dos países membros do G-8 (os sete países mais ricos do mundo, mais a Rússia), em 2003, para desenvolver um novo passaporte (conhecido como e-passport ou passaporte eletrônico), que utilizaria "alta tecnologia para auxiliar no combate contra o terrorismo". ${ }^{11}$ Os Estados Unidos pressionavam, na ocasião, para a adoção do novo sistema pelos países membros do Visa Waiver Program, um programa do governo norte-americano para permitir que cidadãos de determinadas nações (atualmente são 34 e não inclui o Brasil) possam entrar no país para atividades de turismo ou negócios por 90 dias sem a necessidade de visto. Este programa apresenta regras de como qualificar países que estão aptos a requerer sua participação. Entre essas regras está a adoção da biometria nos passaportes e a capacidade nacional de controlar a imigração e as atividades de contrabando.

Para além das conexões com as exigências internacionais, as mudanças no passaporte brasileiro relacionam-se com um contexto importante de formulação de novos discursos e práticas, como pode ser observado na legislação brasileira relativa à utilização de novas tecnologias de segurança.

É importante ressaltar que observar as proposições legais ou normas internacionais sobre o tema 
não significa compreender o funcionamento do poder de forma descendente a partir das instituições, mas sim captar parte dos discursos que circulam sobre o tema, com intuito de fazer emergir um campo de tensões e arranjos que produzem a possibilidade do uso de novos equipamentos de segurança. Não se trata, portanto, de analisar essas tecnologias pelas instituições que a legitimam, nem de afirmar ou negar a necessidade e a validade das tecnologias de vigilância para a segurança, mas de procurar apreender quais são as produções desse processo em curso com base nos discursos veiculados.

Desde meados da década de 1990, notam-se na legislação brasileira argumentos para a obrigatoriedade do uso de câmeras de vigilância - representantes iniciais dessas novas tecnologias - nos mais variados espaços, inicialmente em locais como bancos, ampliando-se para espaços de circulação pública no decorrer do tempo. Os discursos apresentados interagem com os interesses dos empresários do setor de segurança privada, formulando e intensificando o caráter de mercadoria da segurança.

É acelerado o crescimento das empresas de segurança privada no Brasil, tanto no número de empresas e de vigilantes, de especialistas e centros de formação, como do montante que movimentam. Caldeira (2000) e Zukin (1995) observam na comparação entre força policial pública e vigilantes privados a formação de um verdadeiro exército privado. Caldeira também alerta que no Brasil, em 1996, a força policial pública e a vigilância privada tinham contingentes quase iguais. Para Zukin, do ponto de vista da economia política, essa mudança é característica dos processos de privatização em geral, que abrangem não apenas a segurança, mas também a precarização do trabalho ou da saúde, entre outros aspectos.

Durante a pesquisa realizada entre 2002 e 2005 observou-se uma conexão profunda entre a legislação que impulsiona o mercado de segurança e legisladores, muitas vezes ligados a empresas desse setor. Os sistemas eletrônicos de segurança fornecidos por essas empresas tornaram-se uma possibilidade no país no jogo entre o mercado de segurança privada, os legisladores e os interesses de determinados grupos sociais de maior poder aquisitivo, que passaram a formular uma idéia de segurança mais no sentido de medida de proteção pessoal, do que de segurança pública. Tanto os legisladores como os empresários argumentam que as câmeras e a segurança privada são uma necessidade em função da segurança pública inadequada. A ineficiência do Estado, nesse contexto, é um argumento, mas também acaba sendo uma meta para que essa opção privada se perpetue.

Da mesma forma, há um jogo para a circulação internacional da segurança como mercadoria. Empresários do setor entrevistados citaram as experiências internacionais de sistemas eletrônicos de segurança como uma espécie de exemplo a ser seguido. Afirmaram que poucos equipamentos de segurança são desenvolvidos ou fabricados no Brasil, sendo a maior parte importada e apenas montada no país. A isso se liga uma idéia de saturação desse mercado em locais como Japão, Europa e América do Norte, apontando para os mercados em expansão na atualidade - Brasil, Índia, China e Rússia. É importante ressaltar que sistemas de segurança sempre são comercializados em pacotes, nos quais são adquiridos vários equipamentos que se complementam, assim como novos significados de segurança, perigo e risco.

A medida provisória (MP) 184, de julho de 2004 (oriunda do poder Executivo), e o projeto de lei do Senado (PLS) 168 de 2005, de autoria de Tasso Jereissati (PSDB), inauguraram duas mudanças nos discursos até então em jogo. A MP 184, transformada na lei 10.935 , tramitou em regime de urgência para abrir crédito extraordinário aos orçamentos fiscal e de investimento da União, em favor dos ministérios da Justiça, do Transporte e da Defesa, visando à implantação de novos sistemas de segurança nos portos nacionais, exigidos pelo Código de Segurança para Portos e Embarcações (ISPSCode, sigla em inglês) e pela Organização Marítima Internacional (OMI), da qual o Brasil é membro. Este exemplo aponta a transformação da utilização de dispositivos eletrônicos em necessidade e requisito básico para o comércio internacional, para a mobilidade de mercadorias.

Somando essa idéia aos discursos da Icao e do Visa Waiver Program, que focalizam a mobilidade de pessoas, constata-se na legislação brasileira os reflexos do discurso norte-americano de segurança e combate ao terrorismo. As mudanças no passaporte 
brasileiro conjugam-se, então, com o acirramento de certo ideário mundial de segurança, que ganhou força extraordinária após o atentado terrorista de 11 de setembro de 2001, nos Estados Unidos. O período marcado pelo combate ao terrorismo apresenta os mecanismos de monitoramento, vigilância e controle de acesso como imprescindíveis para a sobrevivência, multiplicando-os e popularizandoos na mídia e nas feiras de segurança.

Já o Projeto de lei 168 também insere-se neste contexto da utilização da biometria, na medida em que focaliza a atualização da lei inaugural do tema de dispositivos eletrônicos de segurança no país (lei 7.102, de 1983) e detalha, de forma inédita na legislação, a utilização das câmeras para, em seguida, apenas citar a biometria. O projeto revela a consolidação na legislação federal de algo (o uso de câmeras) que já era observado na prática há pelo menos quinze anos, reservando o capítulo III para tratar especificamente do serviço de vigilância eletrônica monitorada, destinado não mais apenas à segurança patrimonial, mas também de pessoas. Além dessa mudança, o projeto também detalha de forma inédita o funcionamento e alguns dos equipamentos desse sistema, sinalizando sua ampliação. Vale ressaltar que no momento em que as câmeras deixam de ser ocultas e são esmiuçadas numa proposição legal, elas já são consideradas pelo mercado de segurança equipamentos complementares ao sistema, que agora está focalizado nos controles biométricos de acesso. Estes, por sua vez, são apenas citados e não descritos no projeto de lei, num jogo de esconde que perpetua uma relação com o mercado de segurança.

A incorporação da biometria no passaporte brasileiro relaciona-se, então, com a circulação de novos discursos sobre segurança, deslocando significados e construindo saberes. Não raro encontramse hoje técnicos na área de segurança especializados em biometria, sendo que esse universo ainda envolve uma série de outros especialistas que vão da computação ao reconhecimento de padrões.

\section{Construindo perfis}

Diferente dos outros exemplos brasileiros de incorporação da biometria em documentos, a mudança nos passaportes também ocorreu fora do país, e no âmbito internacional provocou debates de movimentos sociais em defesa da privacidade e reflexões entre intelectuais, que tentavam problematizar a questão tanto na América do Norte como Europa. Nos anos de 2003 e 2004, ocorreu um intensa polêmica nos Estados Unidos em função das tentativas de implementação de um programa que envolvia a nova tecnologia nos passaportes e o cruzamento de informações com outros bancos de dados, inclusive comerciais.

Conhecido como CAPPS II, sigla em inglês para Sistema Informatizado de Pré-triagem de Passageiros, o programa foi formulado pela Administração de Segurança do Transporte (TSA) nos Estados Unidos. O debate se deu em torno do objetivo do programa de identificar passageiros de maior risco para procedimentos adicionais de segurança antes que eles embarcassem em aviões. A verificação da identidade do passageiro consistia em realizar uma avaliação de risco utilizando bancos de dados disponíveis comercialmente e informações de inteligência. Em outras palavras, eram cruzados dados contidos nos passaportes com outros bancos de dados com intuito de avaliar o risco que determinados passageiros poderiam representar.

A organização Electronic Frontier Foundation, também dos Estados Unidos, afirmou em sua tentativa de dar visibilidade para a questão:

A U. S. Transportation Security Administration anunciou planos para implementar o CAPPS II, uma controversa forma de traçar o perfil de passageiros e um sistema de vigilância que requer a data de nascimento, o telefone residencial e o endereço residencial antes de o passageiro poder embarcar em um vôo norteamericano. De acordo com o CAPPS II, as autoridades de viagem checariam esses e outros detalhes pessoais, confrontando a informação obtida em bancos de dados governamentais e comerciais e, então, rotulariam a pessoa com um código colorido indicando a gradação do nível de risco de segurança que ela representaria. Baseado na cor designada, o passageiro seria detido, interrogado ou sujeito a buscas adicionais. Se ele fosse designado com 
uma cor/gradação equivocada, poderia ser proibido de voar.

Curry aborda o caso do CAPPS II para sinalizar que a construção de sistema de perfis para a identificação de viajantes potencialmente perigosos só pode existir dentro de um amplo sistema de estereótipos e na divisão da população em grupos, neste caso, não de atributos definidos, mas da propensão de engajar-se em certas atividades consideradas perigosas. A utilização da biometria nos passaportes e a maior capacidade que estes documentos têm hoje seguem o mesmo pressuposto. Para Curry, a vigilância de mobilidades requer também uma exploração de dados mais detalhados para construir narrativas das atividades das pessoas. "O que ele realmente está fazendo? Ele é uma pessoa mentalmente transtornada, desesperada para escapar dos seus problemas, para fugir do país? Ele é um criminoso? É um cubano emigrado, agora saudoso? Ou ele é simplesmente homem de negócios?" (Curry, 2004, p. 485).

Curry também aponta como as técnicas de pesquisa de mercado estão sendo usadas na construção dos sistemas de perfil das companhias aéreas. $\mathrm{O}$ autor sustenta a posição de que um sofisticado sistema é construído nessas conexões de dados pessoais e comerciais a partir de narrativas que incorporam opiniões sobre uma série de comportamentos móveis e padrões considerados aceitáveis ou suspeitos. Ele também argumenta que esses perfis são desenhados não para identificar o viajante "confiável", mas, ao contrário, o viajante "perigoso".

Peter Adey (2004) sinaliza por sua vez, também focalizando a vigilância da mobilidade, que aeroportos são espaços onde ocorre a vigilância e a classificação tanto de objetos como de pessoas; para ele, os aeroportos são como filtros. Nestes espaços ocorre, pois, invasão de privacidade e discriminação categórica como resultado da classificação de passageiros. Os textos desses dois autores fazem parte da edição da revista Surveillance \& Society que trata justamente da vigilância de mobilidades. Os outros artigos da publicação tratam de locais para onde tal vigilância se expande, ou seja, é algo que vai além dos possíveis centros de mobilidade, como aeroportos, chegando a qualquer lugar onde pessoas, objetos ou palavras se movam.
Inspirando-se em Paul Virilio (1996), para quem a segurança deve passar pela imobilização dos corpos, a supressão das vontades e dos gestos, ressalta-se aqui que mais do que sobre gestos ou trajes, as novas tecnologias de vigilância realizam sua função focalizando a mobilidade e os fluxos não apenas quando se trata de locais como aeroportos. Também Davis (1993) sinaliza esses fluxos quando observa a revalorização da cidade "eclipsada por uma reestruturação paralela do espaço eletrônico, igualmente policiado, onde o acesso pago a 'comunidades de informação', banco de dados e assinaturas de serviços por cabo se apropriam de partes da invisível ágora". Ambos os processos, segundo esse autor, espelham a desregulamentação da economia e a recessão de direitos não advindos do mercado.

A pesquisa realizada entre 2002 e 2005 concluiu que observar o processo de inserção de câmeras de monitoramento no centro da cidade levou a uma retomada mais radical do que alguns autores observaram na proliferação de condomínios fechados monitorados em conjunto com a nova forma de gerenciamento das cidades, a saber, o enclausuramento de uma parcela da sociedade em enclaves fortificados (Caldeira, 2000; Davis 1993), que reflete uma idéia de isolamento por meio de um limite "murado". A promoção da "solução" privada de segurança e o monitoramento eletrônico em espaços abertos de circulação pública fazem emergir, para além desse isolamento, investimentos de um grupo social sobre a expansão de sua própria mobilidade. Em outras palavras, um processo de imobilização e desaparecimento de alguns grupos sociais em prol da perpetuação de seu próprio movimento.

No caso do monitoramento do centro da cidade, as pessoas não eram identificadas, mas fluxos eram redirecionados. Também no caso das tecnologias de vigilância relacionadas com as possibilidades do passaporte brasileiro, assim como a triagem de passageiros nos aeroportos, o que se torna visível para o sistema não é o indivíduo, mas grandes perfis. O indivíduo dissolve-se num emaranhado de dados e informações. O que passa a ser explorado é o potencial gerado pela combinação de diferentes dados. O sistema possibilita a criação de estereótipos, e a partir deles é que se pode negar ou permitir acesso, autorizar ou não a circulação internacional. 
Cada vez mais softwares são programados no sentido de realizar essa operação de triagem. Já estão incorporados nele a capacidade de correlação de diferentes bancos de dados e a geração de perfis que serão reconhecidos pelo próprio software como suspeitos ou adequados. Virilio (1996) dá uma pista interessante nesse sentido quando analisa a mudança de perspectiva nas sociedades capitalistas. Ele afirma que a questão da guerra pode ser resumida na questão da velocidade. Com a possibilidade de um ataque nuclear e a redução de seu aviso prévio de 15 minutos, em 1962, para 10 minutos (mísseis balísticos) e 2 minutos (armas guiadas por satélite), em 1972, promove-se uma progressiva contração do tempo, que desloca o poder de reflexão e decisão em favor de uma automação. Nessa configuração, não é mais necessário aviso prévio de um ataque para que se iniciem estratégias de defesa, pois a suspeita já é suficiente para isso.

É nessa contração do tempo que a antecipação ou a prevenção surgem como formas de atuação e funcionamento do poder, elementos que interagem com o foco sobre mobilidades e circulação. Neste cenário em que a velocidade é a medida, Virilio ainda esboça considerações sobre o estado de emergência em que passamos a viver. Nele, antecipação sobrepõe-se à imaginação "até o ponto em que governar seria apenas prever, simular, memorizar as simulações" (Virilio, 1996, p. 131). Vale destacar ainda que as formas de atuação que enaltecem ou focalizam a antecipação e a prevenção esvaziam as decisões de seu caráter político e afastam possibilidades alternativas.

\section{Automação, poder e controle}

Com intuito de abordar as tecnologias de vigilância para segurança como parte de uma tecnologia política atual é necessário distanciar a possibilidade de compreendê-las como um aprofundamento do panóptico de Jeremy Bentham, analisado por Michel Foucault (2000). Em alusão à análise foucaultiana, alguns autores têm se referido aos dispositivos que compõem os circuitos fechados de televisão - de forma geral e não especificamente sobre biometria - como "panóptico universal” (Machado, 1990), "panóptico eletrônico" ou "superpanóptico" (Poster, 1990 apud Wood e Graham, 2002), sinalizando um aprofundamento (por uma via tecnológica) do exercício do poder disciplinar descrito por Foucault. Os autores que analisam as atuais câmeras de monitoramento aproximando-as do panóptico acabam restringindo-se à questão da vigilância e ao princípio da visibilidade obrigatória para os vigiados e invisibilidade do vigilante, como recurso para o adestramento e sua interiorização pelos indivíduos.

Arlindo Machado, por exemplo, parte da instalação de câmeras de monitoramento, que foi abrangendo espaços cada vez maiores, do aeroporto ao trânsito, até os satélites, para afirmar a proliferação e a universalização da vigilância. Ele entende os modernos sistemas de vigilância como uma atualização do panóptico de Bentham, e a difusão crescente de dispositivos, como sua universalização. Assim, tais sistemas realizariam

[...] na era da eletrônica e da informática, o mesmo papel paradoxal da máquina benthamiana, produzindo os efeitos de disciplina propostos por Foucault. Tal como o panóptico de Bentham, os dispositivos eletrônicos de vigilância generalizam para toda a sociedade métodos de coerção nascidos no interior de presídios ou antes apenas localizadamente, na investigação ou repressão policial (Machado, 1990, p. 95).

Apesar de essas tecnologias terem como um de seus efeitos a sensação de contínua visibilidade, provocando a internalização da sensação que prescinde uma vigilância ininterrupta, e de garantirem a invisibilidade de seu observador, elas não se aproximam de práticas e discursos fundamentais para o exercício das disciplinas. Ao relacionarem assim as câmeras de monitoramento com o panóptico, alguns autores instrumentalizam parte do pensamento foucaultiano, mas distanciam-se da genealogia proposta pelo filósofo. Aproximar-se da noção foucaultiana de poder não significa analisar os dispositivos eletrônicos de segurança e controle como vinculados ao panóptico.

Foucault (2002) não analisa o poder em uma atuação essencialmente repressiva ou de negação, 
como algo que emana do Estado, mas sim em sua produtividade ou positividade, na produção de saberes, práticas e técnicas. Com esse foco, em vez de partir do Estado e verificar seu prolongamento na sociedade, ele propõe uma análise ascendente do poder, partindo de seus mecanismos infinitesimais para verificar como são investidos, utilizados ou deslocados. Por essa via, o autor diferencia tipos de exercício do poder, como o de soberania e o disciplinar. Para ele, a teoria do direito e o discurso jurídico-político organizam-se em torno da questão da soberania, estando, portanto, diretamente relacionados com a manutenção das sociedades na Idade Média e centrados na figura do rei.

A partir do século XVIII, uma nova mecânica de poder passa a incidir sobre os corpos de forma diferente do que ocorria na soberania: "docilização dos corpos" e de atitudes, denominada pelo filósofo como "poder disciplinar", o qual se relaciona com o panóptico. Os mecanismos de poder disciplinares não supliciam ou castigam os corpos, como era típico da soberania, mas os adestram, aprimoram e permitem "extrair deles tempo e trabalho, mais do que bens e riqueza (Foucault, 2000, p. 139) por meio de instituições disciplinares, como a escola, a fábrica, o hospital, a prisão, e para além delas. Entre os recursos ou instrumentos ${ }^{12}$ para esse adestramento está a sanção normalizadora - um modelo de penalidade que tem como função a redução dos desvios em direção a uma normalização.

A utilização das tecnologias de vigilância não visa à correção dos desvios por meio de uma rotina rigorosa e repetitiva de exercícios, não há sanção normalizadora, essencialmente corretiva e típica das sociedades disciplinares. Assim, mesmo que a introjeção da sensação de vigilância seja permanente, ou que a invisibilidade do observador continue garantida, o sistema de penalidades historicamente específico da disciplina não está em andamento. As câmeras de monitoramento, os dispositivos biométricos, os saberes e as práticas à eles correspondentes não se vinculam mais ao lugar ou ao tempo adequados para a punição exemplar, e sim à permissão ou à recusa do acesso, que desloca e dilui a punição para o momento sempre imediato da mobilidade, da circulação.

Da mesma forma, em lugar do indivíduo, que era o efeito e a produção do poder disciplinar, o que emerge com essas tecnologias é o fluxo de informações. O foco da vigilância, portanto, não é mais o indivíduo, mas o fluxo, sua cadência, seu movimento, suas conexões de informação, a potencialidade que emerge da combinação de informações e sua mobilidade. Assim, apesar da introjeção da idéia de visibilidade, somente as atitudes que se destacam no fluxo chamam a atenção. É sobre perfis que se opera a visibilidade, sobre figuras que se tornaram representantes de perigo ou de inadequação. No entanto, não se trata mais de um visibilidade que individualiza, mas que sinaliza um erro, um desvio do fluxo, que não será corrigido por uma sanção normalizadora como na sociedade disciplinar.

Regulação da mobilidade, promoção da invisibilidade pela imersão no fluxo e da visibilidade pela representação de inadequação são alguns dos efeitos dessas tecnologias em conexão com outros processos em andamento. Da mesma forma, caracterizam essa forma de funcionamento do poder a contração do tempo, a prevenção e a automação. As tecnologias de vigilância hoje atuam por antecipação de ações, na previsão dos próximos movimentos, operando e agindo nos limites da variação da incerteza.

A atualidade das tecnologias de monitoramento coincide com um funcionamento do poder que não é mais disciplinar, elas participam de uma nova racionalidade política, compõem com novas tecnologias políticas. É importante ter em conta que a visibilidade é formada de linhas de luz que formam figuras variáveis e inseparáveis deste ou daquele dispositivo (Deleuze, 2000). As prisões, os hospitais e as escolas eram instituições vinculadas ao poder disciplinar; eram parte de dispositivos que tinham certo regime de luz e faziam nascer um objeto, que era o próprio indivíduo. Ainda segundo Deleuze, o atual não é o que somos, mas aquilo em que vamos nos tornando:

É necessário distinguir, em todo o dispositivo, o que somos (o que não seremos mais), e aquilo que somos em devir: a parte da história e a parte do atual. A história é o arquivo, é a configuração do que somos e deixamos de ser, enquanto o atual é o esboço daquilo em que vamos nos tornando. Sendo que a história e o 
arquivo são o que nos separa ainda de nós próprios, e o atual é esse outro com o qual já coincidimos (2000, p. 93).

Deleuze (2000) dá a direção também ao afirmar que os indivíduos, identificados por assinatura ou por um número, tornaram-se dividuais, divisíveis, identificáveis por cifras ou senhas, e as massas tornaram-se amostras, dados, mercados ou bancos. Uma nova correlação de forças e novos agenciamentos coletivos relacionam-se com a mutação do capitalismo de concentração do século XIX, com a crise das instituições. Em consonância com este autor, a utilização das tecnologias de vigilância aqui tratadas fazem parte de um dispositivo de poder que funciona muito mais por meio de controle contínuo, via comunicação imediata, num contexto capitalista de sobreprodução, em que se objetivam a compra de ações e a venda de serviços, entre eles, os relacionados com a segurança. Gilles Deleuze também fornece uma chave de compreensão desse panorama ao apontar o marketing como instrumento de controle contínuo e ilimitado.

Por outro lado, afirmar que as tecnologias de monitoramento se aproximam mais do controle do que da disciplina não significa argumentar que não há mais nenhum elemento das sociedades disciplinares na atualidade, mas sim sinalizar esse "outro com o qual já coincidimos". O contexto brasileiro e as desigualdades de nossa sociedade sinalizam elementos disciplinares e de controle. Além disso, também não é possível afirmar que esses tipos de sociedade, como analisadas por Foucault e Deleuze, sucedam-se numa seqüência.

De acordo com Foucault (2006, p. 23), não é possível afirmar que mecanismos de funcionamento do poder sucedam-se de forma a provocar o desaparecimento dos precedentes. Para este filósofo ocorre um aperfeiçoamento das técnicas e uma mudança no sistema de correlação entre mecanismos diferentes. Nesse sentido, uma determinada tecnologia de poder pode colocar em funcionamento dentro de sua própria tática diferentes mecanismos, como se os atualizasse. Em suma, podem conviver mecanismos disciplinares, de soberania ou de controle.

Didier Bietlot (2003) afirma, por sua vez, que no lugar da livre circulação, há uma rede de colabo- ração policial, conexões informáticas, medidas e discursos que edificam um "continuum securitário", o qual abrange, por transferência de legitimidade, "do combate às drogas e ao terrorismo até a imigração e o direito de asilo". Segundo o autor, desde o fim da Guerra Fria, o campo da segurança interna se reconfigurou e, hoje em dia, é a imigração (em especial islâmica) que constitui a ameaça principal e a que deve firmemente fazer face aos dispositivos securitários.

De um lado, as práticas e os discursos neste cenário legitimam as políticas de migração restritivas ou ditas "de imigração zero", de outro, esses dispositivos propagam medo, angústia, sentimentos difusos de insegurança e conforto, fazendo com que a população reclame freqüentemente por mais medidas securitárias.

Vale destacar ainda que Bietlot propõe a existência simultânea de mecanismos de poder disciplinares e biopolíticas (Foucault) aperfeiçoadas com mecanismos de controle (Deleuze), e ainda uma reaparição do velho poder soberano e do Estado permanente de exceção (Agamben) em face das ameaças de insegurança. Passetti (2004) parece percorrer caminho semelhante, sobrepondo controle, disciplina e soberania. No entanto, em Bietlot essa proposta é denominada "sociedade securitária", que sucederia sociedades disciplinares. Para o autor, a desregulação neoliberal criou inevitável e voluntariamente uma situação de insegurança e de incerteza. As desordens sociais engendradas por essa situação fornecem as razões de ser aos seus controles e violências. Os dispositivos securitários encarregar-seiam não somente de prevenir a desordem, mas também de defini-la e, eventualmente, suscitá-la.

Deter-se na sobreposição e não na sucessão de formas de funcionamento do poder pode ser um interessante caminho para as pesquisas na atualidade. A capacidade de vigilância e controle nas sociedades contemporâneas ocidentais, a velocidade de avanço e a obsolescência das tecnologias, os discursos e as representações, os saberes e as práticas associados a este cenário e, mais profundamente, as atuais mudanças no capitalismo conectam-se a importantes transformações sociais. Nesse sentido, as novas tecnologias de segurança tratadas neste artigo, tais como câmeras de monitoramento e dispositivos 
biométricos de controle, configuram-se como um mote para uma aproximação e a análise desse campo premente e fecundo de pesquisas.

\section{Notas}

1 Nesse contexto, vale destacar como exceção brasileira a performance artística "Atitude suspeita", realizada em 2006, pelo grupo Esqueleto Coletivo, visando às câmeras de vigilância instaladas no centro da cidade de São Paulo. Também é importante ressaltar que, no Brasil, pesquisadores e artistas vinculados à área de comunicação têm se voltado nos últimos anos para o tema da vigilância, tais como Bruno (2004, 2006 e 2008) e Leblanc (2009). Também na área de arquitetura e urbanismo tem surgido trabalhos que versam diretamente sobre o tema (Firmino et al., 2009).

2 Cf. documento: "A ficção científica chega até a vida" (s.d.).

3 Cf. documento: "A biometria como processo de segurança”, 2005. Revistas do setor de segurança foram acompanhadas durante a pesquisa sobre câmeras realizada entre os anos de 2002 e 2005 com o intuito de apreender a formulação de saberes, o surgimento de técnicos e cursos de formação que passaram a definir o que é segurança na atualidade e como deve ser gerida. Foram escritos nesse período textos abordando a biometria.

4 "Uma nova tecnologia baseada na biometria deve em breve começar a dispensar a necessidade de memorização de tantas senhas para cartões de crédito, banco e computador, entre outras. Uma rápida verificação da íris ou impressão digital poderá, por exemplo, autorizar uma transação bancária" (cf. documento: "Biometria facilita a vida dos que têm que decorar muitas senhas", 2004).

5 Presente em departamentos de trânsito de vários estados brasileiros, o sistema biométrico teve como justificativa inicial a necessidade de combate à fraude nos procedimentos dos Detrans. Apesar de não ser objetivo deste artigo a avaliação da eficiência desses sistemas, é importante apontar que a persistência das fraudes é parte do debate brasileiro atual sobre biometria. O quadro remete a uma adoção pouco refletida de soluções tecnológicas, sem a devida participação e debate da sociedade civil, e a geração de novos, ou a perpetuação de antigos problemas, para os quais novas soluções tecnológicas ou equipamentos de vigilância ainda mais onerosos são alavancados (cf. documento: "Malha fina do Detran pega 200 autoescolas e 19 mil motoristas", 2008).

6 Cf. documento "Instituto de Identificação demonstra novo sistema: Rondônia é pioneira”, 2009.

7 “O projeto do novo passaporte compreende, além da instituição da caderneta de viagem, um completo sistema de controle a ser instalado em todos os portos, aeroportos e postos de fronteira, além da rede consular no exterior, com leitura mecânica desses documentos na fiscalização do tráfego internacional. O projeto é resultado de parceria do Ministério da Justiça, por meio do Departamento de Polícia Federal, do Ministério das Relações Exteriores, do Serviço Federal de Processamento de Dados - Serpro e da Casa da Moeda do Brasil - CMB" (cf. documento: "Informações sobre o novo passaporte brasileiro", s.d.

8 Idem, grifos meus. Vale lembrar que as idéias de credibilidade internacional e modernização compõem uma justificativa para a importância das mudanças no passaporte. A esse respeito ver a atual pesquisa em curso, que também se preocupa em investigar a funcionalidade e o papel do acionamento dessas idéias no contexto de implementação da nova carteira de identidade (RIC).

9 Cf. documento: "Conheça o novo passaporte brasileiro: elementos do novo passaporte brasileiro”, s.d.

10 O código de barras bidimensional difere do tradicional encontrado em contas bancárias ou produtos de supermercado. Enquanto no tradicional as informações são armazenadas em linha e a quantidade de dados depende do comprimento, no código bidimensional, os dados estão em formato de um quadrado composto por vários outros quadrados menores. Neste caso, os dados são armazenados em linhas e colunas, dando a possibilidade de armazenamento de uma maior quantidade de informações.

11 "Um e-passaporte incorpora dados relativos à identidade de um indivíduo, as diretrizes atuais da Icao requerem que e-passaportes incluam informações de reconhecimento facial. Os contornos dos rostos dos indivíduos são digitalmente mapeados e armazenados em um chip de forma que a comparação da informação facial do portador do passaporte possa ser feita com a informação da pessoa cujo passaporte foi emitido" (cf. documento: Visa Waiver Program, 1990, trad. minha).

12 "O sucesso do poder disciplinar se deve sem dúvida ao uso de instrumentos simples: o olhar hierárquico, a sanção normalizadora e sua combinação num procedimento que lhe é específico, o exame" (Foucault, 2000, p. 143). 


\section{BIBLIOGRAFIA}

ADEY, Peter. (2004), "Secured and sorted mobilities: examples from the airport". Surveillance \& Society, 1 (4): 500-519. Disponível no site <http:/ /www.surveillance-and-society.org/articles1 (4)/sorted.pdf>, acessado em março de 2007. ARVIDSSON, Adam. (2004), "On the "pre-history of The panoptic sort': mobility in market research". Surveillance \& Society, 1 (4): 456-474. Disponível no site <http://www.surveillanceand-society.org/articles1(4)/prehistory.pdf>, acessado em de 2007.

BENNETT, Colin \& REGAN, Priscilla. (2004), "Editorial: surveillance and mobilities". Surveillance \& Society, 1 (4): 449-455. Disponível no site <http://www.surveillance-and-society.org/ articles1(4)/editorial.pdf $>$, acessado em março de 2007.

BIETLOT, Didier. (2003), "Du disciplinaire au sécuritaire: de la prison au centre fermé". Multitudes: Revue Trimestrielle, Politique, Artistique et Culturelle, 11. Disponível no site <http://multitudes. samizdat.net $/$ article.php3?id_article $=103>$, acessado em março de 2005.

BIGO, Didier. (1998), "Sécurité et immigration: vers une gouvernementalité par l'inquiétude?”. Cultures \& Conflits, 31-32: 13-38. Disponível no site $<$ http://www.conflits.org/article.php3?id_article $=326$, acessado em agosto de 2006 .

BRUNO, Fernanda. (2004), "Máquinas de ver, modos de ser: visibilidade e subjetividade nas novas tecnologias de informação e de comunicação". Revista da Famecos, 24: 110-124.

. (2006), "Dispositivos de vigilância no ciberespaço: duplos digitais e identidades simuladas". Revista Fronteiras, Estudos Midiáticos, VIII (2): 152-159.

. (2008), "Tecnologias de informação e subjetividade contemporânea". Revista ComCiencia, 96, mar. Dossiê Temático Indicadores. Disponível no site <http:/ / www.comciencia. br/comciencia $/$ handler.php? section $=8 \&$ edicao $=33$ \&id=384\&tipo $=1>$, acessado em junho de 2008 .

CALDEIRA, Teresa. (2000), Cidades e muros, crime, segregação e cidadania em São Paulo. São Paulo, Editora 34/Edusp.
CURRY, Michael. (2004), “The profiler's question and the treacherous traveler: narratives of belonging in commercial aviation". Surveillance \& Society, 1 (4): 475-499. Disponível no site <http:// www.surveillance-and-society.org/articles 1(4)/ treacherous.pdf $>$, acessado em março de 2007.

DAVIS, Mike. (1993), Cidade de Quartzo, escavando o futuro de Los Angeles. Trad. Renato Aguiar. $1^{\mathrm{a}}$ edição. São Paulo, Página Aberta.

DELEUZE, Gilles. (2000), Conversações. Trad. Peter Pál Pelbart. São Paulo, Editora 34.

FIRMINO, Rodrigo et al. (2009), "Olhos de vidro: observando os observadores no monitoramento de espaços públicos em Curitiba, Brasil". Anais do I Simpósio Interdisciplinar e Internacional Vigilancia, Segurança e Controle Social na América Latina. Curitiba, Pontifícia Universidade Católica, 4 a 6 de março.

FOUCAULT, Michel. (2000), Vigiar e punir: história da violência nas prisões. Trad. Lígia M. Pondé Vassalo. 23 ed., Rio de Janeiro, Vozes.

. (2002), Em defesa do sociedade: curso do Collège de France (1975-1976). Trad. Maria Ermantina Galvão. São Paulo, Martins Fontes. . (2006), Seguridad, territorio, población: curso en el Collège de France: 1977-1978. Trad. Horácio Pons. Buenos Aires, Fondo de Cultura Económica.

LEBLANC, Paola Barreto. (2009), "Composição para circuito de vigilância”. Anais do I Simpósio Interdisciplinar e Internacional Vigilância, Segurança e Controle Social na América Latina. Curitiba, Pontificia Universidade Católica, 4 a 6 de março.

LYON, David. (2006), "9/11, synopticon and scopophilia: watching and being watched", in K. Haggerty e R. Ericson (eds.), The new politics of surveillance and visibility, Toronto, University of Toronto Press.

KANASHIRO, Marta M. (2006), Sorria, você está sendo filmado: as câmeras de monitoramento para segurança em São Paulo. Campinas, dissertação de mestrado, Universidade Estadual de Campinas (mimeo.). . (2007), "Dispositivos biométricos no Brasil: a expansão das novas tecnologias de segurança". São Paulo, Projeto de pesquisa, Programa de Doutorado em Sociologia, Universidade de São Paulo. 
- (2008), "Surveillance cameras in Brazil: exclusion, mobility regulation and the new meanings of security". Surveillance \& Society, 5 (3): 270-289. Disponível no site <http:/ /www. surveillance-and-society.org/articles5(3)/brazil.pdf $>$, acessado em dezembro de 2008.

MACHADO, Arlindo. (1990), "Máquinas de vigiar". Revista USP, 7: 23-32, set.-nov.

PASSETTI, Edson. (1999), "Sociedade de controle e abolição da punição". São Paulo em Perspectiva, 13 (3): 56-66, jul./set. Disponível no site <http:/ /www.scielo.br/pdf/spp/v13n3/v13n3a07. pdf $>$, acessado em dezembro de 2005.

. (2004), "Segurança, confiança e tolerância: comandos da sociedade de controle". São Paulo em Perspectiva, 18 (1): 151-160, jan.-mar.

VIRILIO, Paul. (1996), Velocidade e politica. São Paulo, Estação Liberdade.

WOOD, David \& GRAHAM, Stephen. (2002), "Digitalizing surveillance: categorization, space, inequality". Critical Social Policy, 23 (2): 227-248.

ZUKIN, Sharon. (1995), The culture of cities. Oxford, Blackwell Publishers.

(2000), "Paisagens do século XXI: notas sobre a mudança social e o espaço urbano", in A. A. Arantes, O espaço da diferença, Campinas, Papirus.

. (2003), "Aprendendo com Disney

World”. Espaços e Debates, 23:43-44, jan.-dez.

\section{Documentos consultados}

"A biometria como processo de segurança". (2005), Revista Security, ano VII (51), jun.-jul.

"A ficção científica chega até a vida". (s.d.), Texto da empresa privada de serviços em tecnologia da informação Politec Inteligência em TI. Disponível no site <http://www.politec.com.br/ Internet/portfolio/tecnologias/biometria>, acessado em outubro de 2006.

"A Passport with machine readable capability". (1980), International Civil Aviation Organization, Montreal.

"Biometria facilita a vida dos que têm que decorar muitas senhas". (2004), Folha de São Paulo, Caderno Informática, 15 out.
"CAPPS II: Government Surveillance via Passenger Profiling". (s.d.), Electronic Frontier Foundation (EFF). Disponível no site <http:// www.eff.org/Privacy/cappsii/>, acessado em maio de 2005.

"Conheça o novo passaporte brasileiro: elementos do novo passaporte brasileiro". (s. d.), de Iberê Uchôa de Azevedo Barbosa, Ministério das Relações Exteriores, Brasil. Disponível no site <http:/ /www.abe.mre.gov.br/apoio/Novo $\% 20$ Passaporte.pdf/view $>$, acessado em julho de 2007.

"Detran-SP fecha cerco a donos de auto-escolas por fraude em exames de renoação de carteira de motorista". (2006), Disponível no site < http:/ /www.detran.sp.gov.br/noticias/20060914. asp>, acessado em abril de 2007.

Grupo Esqueleto Coletivo. (s.d.), "Atitude suspeita". Disponível no site <http://atitude-suspeita. blogspot.com>, acessado em março de 2007.

ICAO/MRTD (International Civil Aviation Organization/Machine Readable Travel Documents). Disponível no site <http://mrtd.icao.int/>, acessado em março de 2007.

"Informações sobre o novo passaporte brasileiro". (s. d.), disponível no site <http://www. dpf. gov.br/web/servicos/passaporte_novo. htm>, acessado em julho de 2006.

"Instituto de Identificação demonstra novo sistema: Rondônia é pioneira”. (2009), Jornal O Nortão, 23 mar.

"Malha fina do Detran pega 200 auto-escolas e 19 mil motoristas". (2008), O Estado de São Paulo, Caderno Cidades, 9 mar.

"Projeto básico". Nove documentos disponíveis para download sob a indicação: Instrumento administrativo de apoio ao processo decisório do Tribunal Superior Eleitoral, de consulta à sociedade quando da implantação do Projeto de Atualização do Cadastro de Eleitores - $1^{a}$ fase, nas seguintes unidades da Federação: DF, MA, MG, MT, TO. Poder Judiciário, Tribunal Superior Eleitoral. Disponível no site <http://www. tse.gov.br/institucional/licitacao/audiencia. html>, acessado em dezembro de 2008.

Surveillance Câmera Players. Disponível nos sites <http://www.notbored.org/scp.html > e 
<http://www.notbored.org/the-scp.html>, acessado em julho de 2005.

Surveillance Câmera Players: 1984, vídeo da performance. Disponível no site <http://www. youtube.com/watch?v=RILT18mx EnE $>$, acessado em julho de 2005.

Visa Waiver Program. Disponível no site <http:// travel.state.gov/visa/temp/without/without_ 1990.html>, acessado em março de 2007.

Visa Waiver Program. "How a Country Qualifies?”. Disponível no site <http:/ / travel.state.gov/visa/ temp/without/without_1255.html>, acessado em março de 2007. 

MOBILIDADE COMO FOCO DAS
TECNOLOGIAS DE VIGILÂNCIA

\section{Marta Mourão Kanashiro}

Palavras-chave: Vigilância; Tecnologia; Poder; Mobilidade; Representação social.

As tecnologias de vigilância e o monitoramento para a segurança, recorrentes nas sociedades contemporâneas ocidentais, conectam-se a importantes transformações sociais e a diferentes temas pesquisados nas ciências sociais. Compreendidas como parte de dispositivos de funcionamento do poder, as câmeras de vigilância e as novas tecnologias, como a biometria incorporada aos passaportes, não se vinculam mais à punição exemplar da sociedade disciplinar foucaultiana, e sim à permissão ou à recusa do acesso. Como parte de uma pesquisa em andamento, que tem como um de seus focos a biometria incorporada em documentos, este texto faz um levantamento de algumas abordagens que analisam mobilidade, tecnologias de vigilância e circulação internacional de pessoas, com novas representações e definições de perigo e insegurança.

\section{MOBILITY AS FOCUS OF SURVEILLANCE TECHNOLOGY}

\section{Marta Mourão Kanashiro}

Keywords: Surveillance; Technology; Power; Mobility; Social representation.

Surveillance and monitoring technologies for security, recurrent in contemporary western societies, are connected to important social transformations, and to different themes studied in social sciences. Understood as power devices, surveillance cameras and new technologies such as biometrics embedded in passports, are no longer related to exemplary punishment as in foucaultian disciplinary society. They now relate to permission or denial of access, which displaces and dilutes punishment away to time and space of mobility or circulation. As part of an on going research, which has biometrics embedded in documents as one of its themes, this paper tracks some approaches that connect mobility, surveillance technologies and the movement of people worldwide with new representations and definitions of risk and uncertainty.

\section{LA MOBILITÉ EN TANT QUE POINT FOCAL DES TECHNO- LOGIES DE VIGILANCE}

\section{Marta Mourão Kanashiro}

Mots-clés: Surveillance; Technologie; Pouvoir; Mobilité; Représentation sociale.

Les technologies de surveillance et de monitoring de sécurité, courantes dans les sociétés contemporaines occidentales, sont liées à d'importantes transformations sociales et à différents thèmes d'études en sciences sociales. Comprises comme des dispositifs de pouvoir, les caméras de surveillance et les nouvelles technologies, telle que la biométrie incorporée dans les passeport, ne sont plus associés à la punition exemplaire de la sociéte disciplinaire foucaultienne, mais à l'autorisation ou non à un droit d'accès, qui déplace et dilue la punition dans un moment toujours immédiat de la mobilité et de la circulation. Comme partie d'une étude en cours, qui a entre autre point central la biométrie incorporée dans des documents, ce travail fournit un inventaire d'abordages qui relient mobilité, technologies de surveillance et circulation internationale des personnes avec de nouvelles représentations et définition du danger et de l'insécurité. 